\title{
Novel Applications for Greenhouse Gases (GHGs) for Municipal and Industrial Wastewater Treatment Technologies
}

\author{
Ahmed Eldyasti \\ Department of Civil Engineering, Lassonde School of Engineering \\ York University \\ Toronto, Ontario, Canada \\ Ahmed.eldyasti@lassonde.yorku.ca
}

Billion of dollars are spent annually for operating and maintenance costs to reduce the greenhouse gases for waste and wastewater treatment plants in Canada, while current society demands for clean and safe environment have been increasing. In parallel, energy security and climate change mainly caused by anthropogenic activities have become a national and international issue to be addressed. In 2016, waste management sector has contributed by $3.4 \%$ of Canada's total GHG emissions. On the other hand, waste treatment plants (WTPs) are considered extensively energy demanding facilities, for instance, sewage treatment facilities only have consumed more than $22 \%$ of the total electrical demand of Toronto city facilities in 2016. Thus, it is pivotal to develop sustainable technologies not only for waste treatment or mitigation of the resulted GHG, but also for value-added resources and energy recovery from different waste streams.

Anaerobic digestion process has been widely adopted by WTPs for waste minimization and biogas production. Nevertheless, multiple obstacles limit the direct use of the produced biogas such as the presence of impurities and its low handling and collecting capabilities. Those obstacles drive most of the sewage treatment facilities to flare the produced biogas. In the city of Toronto only, $90,000 \mathrm{~m} 3$ biogas/day is produced from wastewater treatment facilities, which indicates how large and vital is the biogas either as a pollutant or an energy resource.

Research on new Gas mitigation technologies for upgrading municipal and industrial wastewater treatment plants and the treatment of internal side streams without the need for expansion of the existing volumes is therefore essential. Furthermore, the emerging trend of reducing power consumption and carbon footprint for wastewater treatment plant is driving technology development. The new generation of such treatment processes will include the application of sustainable novel biological shortcut nutrient removal reactors coupled with the recovery of the value-added products and energy that are generated in such a process, as well as the use of energy-efficient processes to transform "energyconsuming treatment processes" into "energy-saving and energy-positive systems". The primary focus of this talk is to provide a high-level overview of the next generation of wastewater treatment plants using biofilm processes and their integration to maximize energy and value-added products recovery, including biomethane, biohydrogen, and biopower, in accordance with the emerging paradigm shift towards mining resources from wastewater. 